\title{
REGULAÇÃO BANCÁRIA: UMA ANÁLISE DE SUA DINÂMICA POR OCASIÃO DOS DEZ ANOS DA CRISE FINANCEIRA GLOBAL
}

\author{
Ana Rosa Ribeiro de Mendonça ${ }^{a}$ \\ Simone Deos $^{b}$ \\ aProfessora livre docente do Instituto de Economia da Universidade Estadual de Campinas (Unicamp) e \\ pesquisadora do Centro de Estudos de Relações Econômicas Internacionais (CERI) da Unicamp. \\ Campinas, SP, Brasil. ORCID: http://orcid.org/0000-0003-3521-188X.

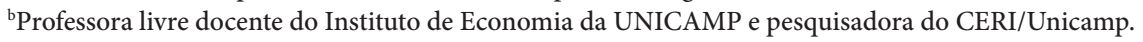 \\ Campinas, SP, Brasil. ORCID: https://orcid.org/0000-0003-1134-0871.
}

Recebido em 11 de março de 2019

Aceito em 02 de dezembro de 2019

RESUMO: O presente artigo procura refletir sobre a dinâmica da regulação financeira internacional - bancária, em especial. O ensejo para a reflexão são os dez anos da crise financeira global. Para tal, parte de uma análise conceitual sobre bancos, sistemas bancários, riscos e regulação, apontando que o movimento regulatório precisa ser pensado num contexto amplo, que leve em consideração diferentes estágios do capitalismo. Na sequência, procura analisar os impactos da crise sobre a regulação bancária. Isto posto, o que se observa, em geral, é um movimento pendular, oscilando entre momentos em que a regulação proposta é mais pró-mercado e momentos nos quais ela impõe um conjunto mais importante de barreiras e interdições. Ademais, independentemente do "regime regulatório" do qual se parta, o que se observa é que a dinâmica concorrencial tende a corroer endogenamente o aparato regulador vigente, redefinindo-o na direção da criação de maior fragilidade financeira.

PALAVRAS-CHAVE: bancos; sistema bancário; riscos bancários; regulação bancária; crise financeira global.

CLASSIFICAÇÃO JEL: E42; E44; E58.

Correspondência para: Ana Rosa Ribeiro de Mendonça

Contato: anarosa@unicamp.br 


\section{BANKING REGULATION: AN ANALYSIS OF ITS DYNAMICS BROUGHT ABOUT BY THE $10^{\text {TH }}$ ANNIVERSARY OF THE GLOBAL FINANCIAL CRISES}

SUMMARY: This paper aims to analyze the dynamics of financial regulation mainly banking regulation - on an international level. It takes the 10th anniversary of the Global Financial Crises as an opportunity for this reflection. To do that, the first step is a conceptual analysis of banks, banking systems, risks, and regulation, pointing out that the swings on regulation have to be understood in a broader context, which takes into consideration the different stages of capitalism. Following that, the paper tries to assess the impacts of the GFC on banking regulation. That said, one can notice that regulation moves like a pendulum, swinging from a more pro-market framework to another in which the regulation imposes more barriers to the functioning of banks. Besides, the paper points out that, no matter from where you depart in terms of a more or less pro market regulation, competition among banks will pressure the regulatory framework, leading to a less regulated and more fragile environment.

KEYWORDS: banks; banking system; banking risks; banking regulation; global financial crisis. 


\section{INTRODUÇÃO}

O ano de 2008 testemunhou o ápice de um processo de fragilização financeira, num movimento que vinha dando sinais nítidos de agravamento pelo menos desde o ano anterior e que se transformou em crise aberta com o pedido de falência do banco de investimento americano Lehman Brothers, no dia 15 de setembro daquele ano. A partir daí, explicitou-se um fenômeno amplo e profundo de contágio e exacerbação da incerteza, que levou à paralisação dos mercados, ao desaparecimento da liquidez, ao colapso no preço dos ativos e ao congelamento do crédito. Ainda que tenha se originado nas economias centrais, a chamada crise financeira global (CFG) teve impactos sobre muitas economias ao redor do mundo.

Tanto as causas da crise, quanto suas consequências podem ser analisadas sob diversos pontos de vista - da economia, da política, da cultura - uma vez que, mesmo sendo um fenômeno do campo da economia, se entrelaça com aspectos mais amplos da sociedade. Ainda que esteja longe de ser um tema esgotado, as origens da crise, do ponto de vista da economia, foram bastante exploradas. Adicionalmente, a CFG ensejou a inserção de autores à margem do mainstream econômico na discussão. As ideias de Hyman Minsky, um expoente na tradição keynesiana, vieram especialmente à baila. Para alguns, 15 de setembro de 2008 teria sido o "momento Minsky". Contudo, conforme sublinha Wray (2009), a grande novidade teórica de Minsky não foi apontar que crises financeiras ocorrem, e nem mesmo desvendar o que acontece após o seu espocar. O desenrolar da crise em si, o debt-deflation, já estava elucidado pelo menos desde a clássica contribuição de Irving Fisher, do início da década de 1930, quando este autor se debruçou sobre o crash de 1929. A grande contribuição de Minsky foi apontar que a fragilidade financeira, e por isso a possibilidade da crise, vai sendo construída endogenamente, na fase ascendente do ciclo. Assim, apesar da expressão Minsky moment ter alcançado notoriedade, a abordagem do autor talvez fosse mais bem capturada, de acordo com Wray (2009), pela expressão “o meio século de Minsky”.

Por outro lado, as consequências da CFG ainda estão se desdobrando e vão constituindo novos problemas a serem investigados. É fato que os impactos da crise se fizeram, e ainda se fazem sentirem várias dimensões da sociedade, bem como em diferentes países e regiões. De acordo com o World Economic Outlook (WEO) de 2018, houve crise bancária em 24 países no biênio 2007-2008, sendo 18desses considerados economias avançadas. Em 2009, em consequência dos graves acontecimentos do ano anterior, 91 economias, que então representavam dois terços do PIB global, tiveram queda no nível de produto (IMF, 2018a, p. 73). Em aproximadamente 85\% das 24 economias nas quais foram registradas crises bancárias, a trajetória de crescimento do produto, desde a crise até 2018, mostrou um desvio negativo, relativamente à tendência que se observava no pré-crise (IMF, 2018a, p. 74). 
Crises financeiras importantes, em função de seus impactos sobre a economia e a sociedade, suscitam alterações na regulação das finanças. No Global Financial Stability Report (GFSR), de outubro de 2018, o Fundo Monetário Internacional aponta que a CFG levou a uma revisão da regulação das finanças em nível mundial. Novos padrões, ferramentas e práticas foram desenvolvidos e implementados. Porém, a questão que se coloca, de acordo com o GFSR, é se o mundo está mais seguro uma década após a crise financeira global. De acordo com o documento, o sistema bancário tornou-se mais forte com o reforço no quadro regulatório, mas novas vulnerabilidades emergiram, e a estabilidade financeira global ainda está por ser testada (IMF, 2018b).

O objetivo do presente trabalho é analisar a dinâmica da regulação bancária no âmbito dos acordos de Basileia, em especial as transições entre Basileia I e II e entre Basileia II e III. Para tanto, está organizado em duas seções, além desta introdução e de considerações finais. A seção seguinte (Seção 1) apresenta uma discussão conceitual sobre bancos, suas particularidades e riscos associados ao seu funcionamento, bem como sobre a necessidade e o papel da regulação bancária, a partir de um conjunto de autores de tradição keynesiana. Especificamente, trabalhos do professor Fernando Cardim de Carvalho (CARVALHO, 2005, 2007, 2014, 2015; CARVALHO et al., 2015) são recuperados e servem de base para a análise. Destaca-se que, diferentemente do que ocorreu em crises anteriores, na CFG não houve ruptura do sistema de pagamentos, que é operado pelos bancos. Por outro lado, o que se viu de forma clara foi a centralidade dos bancos na oferta de crédito, tendo sido o credit crunch uma dimensão notável da crise, com repercussões deletérias sobre os níveis de produto e de preço dos ativos. De fato, como os bancos precisam sustentar seus ativos tendo acesso constante aos mercados de liquidez, dado o temor generalizado de default, os mercados líquidos também paralisaram forçando a desalavancagem bancária, que se espraiou para a economia como um todo. O que se observou, enfim, foi o entrelaçamento de uma crise de solvência com uma crise de liquidez, que levou a uma forte contração do crédito, redirecionando o debate sobre quais seriam os riscos mais importantes que adviriam de uma crise no sistema bancário. São também discutidas, nessa seção, a hipótese da instabilidade financeira de Minsky, bem como sua articulação com a reflexão, do mesmo autor, sobre transformações institucionais de mais longo prazo. Para Minsky (1990, 1993), a partir dos anos 1970, inaugurou-se um estágio do capitalismo relativamente mais instável que o anterior. No interior dessa moldura histórica e institucional ampla, outro fenômeno vai tomando corpo: a geração da fragilidade financeira endógena, a qual pode se desdobrar em instabilidade ou crise.

Na Seção 2 o tema é a regulação de Basileia. O objetivo não é detalhar cada um dos Acordos, já amplamente discutidos na literatura. O que se busca, à luz de autores centrais, é compreender seu movimento - sobretudo a transição de Basileia I para Basileia 
II e de Basileia II para Basileia III. Para isso, é destacado um conjunto de trabalhos de Cardim de Carvalho $(2005,2014,2015)$ que iluminam o fenômeno com profundidade e argumentos originais. De forma sintética, pode-se afirmar que, com a introdução das regras de Basileia, os bancos foram obrigados a manter um montante de capital proporcional não só ao volume de suas posições ativas, mas também ao montante de riscos associados a elas. Enquanto Basileia I era uma regulação bastante simples e de natureza prescritiva - uma vez que composta por um pequeno número de categorias de ativos/riscos -, Basileia II trouxe uma estrutura complexa que aproximou a regulação do comportamento dos agentes. Enquanto Basileia I buscava, sobretudo, nivelar o jogo da concorrência bancária em âmbito internacional, Basileia II apresentava, no centro de suas preocupações, a questão da estabilidade financeira. Porém, a implementação do segundo Acordo foi "atropelada" pela crise de 2008, e a esta se deu Basileia III como resposta. O terceiro Acordo teve como ponto de partida Basileia II, mas exigiu mais e melhor capital para fazer frente aos ativos ponderados pelos riscos. Paralelamente, introduziu novos requerimentos de capital e, cabe notar, impôs exigências de liquidez e restrições à alavancagem.

$\mathrm{Na}$ seção final são retomados pontos discutidos ao longo do texto e procura-se responder a uma nova questão. Partindo da discussão feita nas seções anteriores, busca-se compreender a trajetória da regulação na década seguinte à crise: 2008-2018. A CFG abriu uma disputa sobre quais os caminhos possíveis para a regulação: ajustes no modelo vigente ou redefinição de modelo? Nesse sentido o que se observou, após a crise de 2008, foi uma resposta que, de um lado, representou um movimento de maior restrição ao funcionamento livre dos bancos, relativamente a Basileia II. Contudo, não houve uma redefinição do modelo das finanças, como ocorrido após a grande crise dos anos 1930. Ademais, o que se observa é que a própria regulação imposta após a crise vem sendo transformada pela passagem do tempo e pela dinâmica de funcionamento dos agentes, imersos no business as usual.

No presente trabalho, adota-se a hipótese de Minsky (1994), também presente em Carvalho (2014), de que o movimento da regulação é cíclico ou pendular. Em situações de crise, nas quais a estabilidade do sistema é posta em xeque, observa-se a intensificação da regulação, como ocorreu nos anos 1930, após o crash de 1929, e também mais recentemente, após a CFG. Na medida em que a crise vai se tornando parte do passado, esse arcabouço regulatório mais restritivo, com os custos e as interdições que embute, passa a ser questionado. Nesse movimento, os agentes financeiros - bancos entre eles -, imersos na dinâmica da concorrência intercapitalista, vão inovando em termos de produtos, mercados e práticas em geral. Com isso, e "por dentro", a regulação vai sendo crescentemente tensionada e transformada. Contudo, é preciso também observar os movimentos na regulação a partir de uma lente de alcance profundo, que 
capture a dinâmica das estruturas financeiras - ou, em uma ótica minskyana, das estruturas capitalistas - de forma mais ampla.

Por fim, vale destacar que o trabalho procura recuperar e organizar a larga contribuição de Cardim de Carvalho acerca da regulação financeira, em especial sobre a transição entre as diferentes versões dos Acordos de Basileia.

\section{BANCOS, RISCOS, FRAGILIDADE E REGULAÇÃO}

Bancos estão sujeitos a aparatos regulatórios mais desenvolvidos do que outras instituições atuantes nos diferentes segmentos das economias, ${ }^{1}$ o que pode ser justificado pela presença de peculiaridades na natureza das operações realizadas e também pelo papel histórico e, em geral, pela posição de destaque que essas instituições ocupam em diferentes sistemas financeiros. Entre tais peculiaridades destacam-se aquelas que explicam a suscetibilidade de bancos à crise, assim como à possibilidade de movimentos de contágio que possam gerar risco sistêmico, o que pode ser pensado em dois níveis: sistema financeiro e, de forma mais ampla, sistema econômico. Em geral, tal discussão se constrói a partir da centralidade dos bancos na organização dos sistemas de pagamentos - pois são receptores e criadores de depósitos à vista, instrumentos plenamente líquidos - e, dessa forma, pelo papel que têm na mediação de uma miríade de transações, seja em mercados de bens e serviços, seja em mercados de ativos. Contudo, a CFG mostrou claramente o papel central que os bancos ocupam no financiamento de posições ativas dos agentes, tanto por meio do mercado de crédito tradicional, quanto por meio do carregamento de instrumentos diversos em suas carteiras de ativos. Para desempenhar seus distintos papeis, os bancos operam fortemente alavancados e, em geral, são transformadores de prazos. ${ }^{2}$ Ademais, suas operações são alicerçadas em confiança, pois os contratos financeiros, estejam esses nas carteiras de ativos ou de passivos dos bancos, são transações que envolvem obrigações e direitos a serem exercidos em data futura - em sua grande maioria, significam "dinheiro hoje" combinado com promessa de "dinheiro no futuro".

Posto isso, algumas considerações podem ser tecidas. Em primeiro lugar, como essas instituições ocupam papel central nos sistemas de financiamento de posições e de pagamentos, bem como nos mercados interbancários, dada a natureza das opera-

\footnotetext{
1 Aparatos esses que, em geral, não consideram os desdobramentos da interpenetração crescente entre as funções de bancos e não bancos.

2 Em geral, assumem posições ativas mais longas que as passivas.
} 
ções, com elevados níveis de alavancagem e descasamentos de prazos, a credibilidade é fundamental. Nesse contexto, uma quebra de confiança em determinada instituição pode levar a reações adversas entre os agentes, pressionando seus balanços. Movimentos de contágio podem ser criados, gerando problemas sistêmicos, os quais podem transbordar, levando a uma crise sistêmica.

Em segundo lugar deve-se ter em consideração a lógica que pauta as decisões de composição das carteiras de ativos e passivos dessas instituições. Como agentes capitalistas, os bancos buscam, de forma incessante e crescente, a valorização de capital, em ambiente marcado pela incerteza e em quadro de concorrência acirrada. Essa dinâmica pode significar, e em geral significa, a assunção exagerada de riscos por parte das instituições. E os resultados desse movimento podem gerar efeitos sistêmicos adversos.

As peculiaridades destacadas acima acabam por justificar a presença de regulação e supervisão prudenciais relativamente maiores sobre o sistema bancário, relacionadas à busca pelo que se denomina de solidez ou higidez. ${ }^{3}$ Os quadros regulatórios podem ser pensados, de fato, a partir de dois recortes distintos. Em um primeiro, figurariam instrumentos e mecanismos que podem ser acionados uma vez que os problemas já tenham se instalado, de forma a suavizar seus efeitos e evitar movimentos de contágio, conformando uma rede de proteção. Entre esses, destacam-se a atuação de emprestador em última instância e a presença de seguros de depósito. Numa segunda dimensão estariam normas e regras dos aparatos de regulamentação prudencial, os quais reforçariam a capacidade do sistema para evitar crises. Esses aparatos devem ser acompanhados por normas de monitoramento e supervisão.

No arcabouço conceitual desenvolvido por Minsky $(1975,1986)$, agentes econômicos são entendidos como balanços, compostos por ativos e passivos. Decisões acerca da composição de suas carteiras de ativos e passivos são fundamentais, uma vez que relacionam a renda esperada da posse de um conjunto de ativos com o serviço dos passivos necessários para financiar tais posições ativas ao longo do tempo. Sendo assim, a robustez de suas posições depende de dois fatores centrais: nível de alavancagem e de descasamento de prazos entre ativos e passivos. Ampliar quer a alavancagem, quer o descasamento de prazos, possibilita a elevação dos ganhos, mas implica maior exposição aos

\footnotetext{
3 Carvalho et al. (2015) destacam a importância do sistema financeiro, em especial bancário, e de sua regulação, mas amparados no conceito de externalidades. As atividades bancárias resultam em externalidades positivas e negativas, interdependentes. Essas justificariam a presença de um conjunto de regras e mecanismos para dar suporte ao funcionamento do sistema, cuja estabilidade traz efeitos mais amplos para a sociedade do que os resultantes das operações em si. Entre as externalidades positivas, os autores destacam a organização e a gestão do sistema de pagamentos e as operações de crédito, dada importância delas para o funcionamento das economias. Entre as negativas, estão o risco sistêmico e os movimentos de contágio.
} 
riscos de iliquidez e insolvência. A fragilidade financeira dos agentes individuais resulta, assim, dos riscos de iliquidez e de insolvência que derivam de seus posicionamentos. O grau de instabilidade da economia como um todo, por sua vez, resulta das posições de carteira dos agentes individuais e das conexões entre elas. Vale notar que as decisões dos agentes acerca de seu balanço são tomadas em ambiente de incerteza, o que marca a forma como os agentes tecem suas expectativas. ${ }^{4}$ Para Minsky $(1975,1986)$, as expectativas são formadas tendo como base as experiências recentes. Em períodos de prolongada estabilidade, os agentes tendem a assumir que essa irá perdurar ainda por muito tempo, o que acaba por levá-los a posições de maior risco. A tendência, assim, é de os agentes assumirem maior exposição aos riscos de iliquidez e de insolvência, sendo a estabilidade, ela mesma, desestabilizadora. Eis aí o cerne da chamada hipótese da instabilidade financeira (HIF). A fragilidade desenvolve-se se a partir do movimento normal dos agentes, que tendem a comportamentos de maior risco à medida que se desdobra a fase ascendente do ciclo econômico-financeiro, quando vão sendo erodidos os "colchões de segurança"5 (MINSKY, 1986; KREGEL, 1997).

A construção de Minsky $(1975,1986)$, que parte do posicionamento de agentes econômicos em geral, nos ajuda a pensar o comportamento de instituições financeiras, em especial bancárias, no que tange aos seus riscos específicos.

No âmago de suas operações encontram-se posições fortemente alavancadas e o desencontro de prazos e, dessa forma, a exposição aos riscos de iliquidez e insolvência ocupa papel central. Em situações de estabilidade, esses agentes tendem a assumir po-

4 Em uma referência ao proposto pela hipótese das expectativas racionais, Carvalho (2014) destaca que, em contexto de incerteza, as decisões de exposição não são totalmente racionais, o que não significa agentes são irracionais e que não se amparam nas informações disponíveis, mas que têm consciência de que essas não necessariamente serão suficientes para prever o futuro.

5 Minsky $(1975,1986)$ destaca a importância das margens de segurança - ativos líquidos na carteira dos agentes e folga nas receitas esperadas - para o processo endógeno de alteração de expectativas que leva a um aumento da fragilidade financeira. Na verdade, o autor vai mais longe ao afirmar que "(...) the robustness or fragility of the financial system depends upon the size and strength of the margins of safety and likelihood that initial disturbances are amplified" (1986, p. 233, grifos nossos). Isso ocorre porque o financiamento externo de decisões de investimento leva a uma maior articulação entre fluxos de receitas e de pagamentos que derivam de posições passivas. E o crescimento do financiamento de posições ativas de instituições financeiras, famílias e empresas - característico de momentos de boom - leva um número crescente de agentes a depender do funcionamento "normal" dos mercados financeiros. O acesso dos agentes a tais mercados, no que diz respeito a volumes, preços e colaterais exigidos, é afetado por suas classificações de risco, as quais, por sua vez, dependem do tamanho e robustez das margens de segurança. Dessa forma, um encolhimento dessas margens - que pode resultar da necessidade de fazer frente a desencontros, mesmo que temporários, entre fluxos de receita e compromissos financeiros - pode deteriorar as condições de acesso aos mercados, fragilizando ainda mais tais margens. Isso torna o sistema financeiro mais suscetível aos efeitos de movimentos adversos que, anteriormente, não o afetariam na mesma proporção, ou seja, mais propenso a crises. 
sições crescentemente arriscadas. Isso porque partem da premissa de que o futuro será uma repetição do passado recente, quando na verdade o sistema está em permanente flutuação, oscilando entre expansão, contração e eventuais crises.

Ademais, a ideia de que a estabilidade é desestabilizadora pode ser pensada como uma referência, não somente ao comportamento dos agentes com relação aos riscos, como também ao aparato regulatório. Quanto mais longa for a estabilidade e, de forma mais clara, quanto mais distante se estiver dos problemas que estimularam determinado conjunto de regras, mais este passa a ser questionado pelos agentes, seja por meio de inovações, seja pode meio de pressões para alterações. Nas palavras de Carvalho (2014),

Perhaps the strongest element in the overall pro-liberalization environment was, however, memory. As Minsky stressed many times, when memories of adverse shocks fade, and they all do sooner or later, no matter how important the shock and its consequences, institutions created to defend against those shocks inevitably have their necessity questioned. That was the meaning of his perhaps most famous aphorism, stability is destabilizing. According to this thesis, the very success of the institutions created to prevent a financial crisis that could lead to a new depression, in the long term, will lead people to ask themselves if the costs and/or constraints imposed by these institutions are still worth it. (p. 351)

Para além da HIF, como apontam Tymoigne e Wray (2014), Minsky (1990, 1993) desenvolveu uma abordagem que aponta diferentes estágios na evolução do capitalismo centrada na evolução das finanças. ${ }^{6} \mathrm{O}$ autor, na trilha de clássicos da economia, nos quais se inspirava - Schumpeter entre eles -, pensava o capitalismo como um sistema em constante evolução ou transformação. Para Minsky, os anos 1970, sobretudo nos Estados Unidos, foram marcados pela emergência de transformações que levaram a um novo estágio: o money manager capitalism (MMC). Nele, o setor financeiro desempenhou - e ainda desempenha- um papel crucial e bastante distinto de sua performance em períodos anteriores. Inovações como a securitização e a utilização crescente de derivativos, bem como a existência de bancos muito grandes e integrados - verdadeiros "supermercados financeiros", oferecendo ampla gama de produtos e serviços entre outras, que caracterizam o MMC, tornaram a dinâmica de curto prazo, já marcada pela instabilidade financeira endógena, relativamente mais perigosa e propensa a

6 Tal abordagem serviria como referência para analisar transformações de mais longo prazo, enquanto sua mais conhecida hipótese da instabilidade financeira (1986) daria elementos para a compreensão da dinâmica cíclica de curto prazo. 
crises. Nessa institucionalidade, episódios de instabilidade aconteceriam com mais frequência e seriam mais fortes (MINSKY, 1990, 1993; TYMOIGNE e WRAY, 2014).

Por sua vez, o MMC desdobrou-se a partir de um estágio anterior - relativamente menos instável - do capitalismo. De acordo com Tymoigne e Wray (2014):

The emergence of Money Manager Capitalism was not an accident; it was the outgrowth of the changes that occurred during the postwar stability of Managerial Capitalism. This stability created dynamics that led economic units to make mores risks on the asset and liability side of their balance sheet, and also made them more inclined to trust the guidance of market mechanism in economic affairs. (p. 51)

A estabilidade é, assim, desestabilizadora. A regulação com a qual se inaugurou o estágio do "capitalismo domado", nos anos 1930, vai sendo corroída pelas inovações praticadas pelos agentes e pela ação dos policy makers.

Outro passo importante nessa discussão conceitual, dentro da tradição de KeynesMinsky, foi dado por Carvalho (2014), que por sua vez recuperou trabalho seminal de Kregel (1998) sobre bancos. Para este último, a combinação das posições passivas e ativas dos bancos, da captação por meio de depósitos, bem como da concessão de empréstimos, os levaria à assunção de risco de iliquidez, mas também possibilitaria o que o autor denomina "alquimia bancária": a capacidade de criar riqueza do nada. Essa alquimia resulta, por um lado, da já amplamente discutida capacidade de criação de depósitos à vista, moeda plenamente líquida, por parte dos bancos, independentemente de poupança, ou mesmo de captação prévia. Complementa esse processo alquímico, de acordo com Kregel (1998), a própria formação de capital dos bancos modernos, tal como pode ser observado ao longo do processo de evolução histórica dos bancos no ocidente. De acordo com o autor, o capital dos bancos foi formado ex post, isto é, posteriormente à constituição dos seus ativos e à percepção da possibilidade de determinar o valor presente desses ativos por meio da capitalização das receitas futuras, esperadas. Sendo o valor dos ativos apurado a partir das rendas esperadas, trazidas a valor presente, o capital foi constituído, por sua vez, a partir da venda das participações nesses ativos. ${ }^{7}$ Para Carvalho (2014), um resultado claro que se depreende

\footnotetext{
Kregel (1998) aponta como se deu o processo de capitalização de bancos em diferentes regiões e momentos históricos. Chama atenção do autor como se deu a alquimia do capital na criação de bancos norteamericanos, caso limite do leque de experiências por ele analisadas. Tais bancos teriam se capitalizado sem mesmo ter a posse de ativos que gerassem qualquer tipo de renda. E o fizeram por meio da emissão de ações - que não necessariamente teriam que ser pagas imediatamente. Empréstimos seriam então feitos aos compradores de ações, tendo as próprias ações como colaterais (p. 6).
} 
dessa construção é que "banks capital is conceptually a much less important variable than is usually assumed. A modern bank does not need capital"' (2014, p. 359).

Isso posto, qual seria o poder de um arcabouço regulatório amparado em requerimentos de capital? E, mais ainda, que pondere a exigência de capital pelo montante de riscos assumidos? Se a imposição de requerimentos de capital pode, de alguma forma, afetar as decisões dos agentes, não ficaria claro, para Carvalho (2014), quão eficiente esta seria para limitar a tendência a comportamentos especulativos dos bancos. Partindo da percepção já exposta de Minsky, de que a própria estabilidade induziria os agentes - bancos entre eles - a assumir posições crescentemente arriscadas, em que medida essas posições seriam inibidas se as eventuais perdas delas decorrentes seriam impostas aos seus acionistas, que não são, necessariamente, os tomadores de decisões? Outra questão suscitada é como um arcabouço regulatório que é centrado em exigência de capital lida com o risco de iliquidez, que é inerente às operações bancárias, alavancadas e com descasamentos de prazos? Para Carvalho (2014), sendo o capital bancário teórica e historicamente irrelevante, na verdade seria a liquidez - e os riscos a ela associados, envolvidos na captação de curto prazo (depósitos) e na transformação de prazos - a variável central para a determinação da segurança das atividades dos bancos. E que deveria, dessa forma, ser objeto de grande preocupação dos reguladores.

\section{ACORDOS DE BASILEIA I, II E III: QUAL FOI O MOVIMENTO?}

Ao longo de um amplo período, inaugurado após a grande crise da década de 1930, a regulamentação prudencial apoiava-se em regras que restringiam, em algum nível, a atuação das instituições. Entre as questões enfrentadas pela regulação, a relativa iliquidez das posições ativas dos bancos, vis-à-vis as passivas, ocupava papel importante. Muitos dos instrumentos regulatórios visavam evitar que os bancos enfrentassem problemas de liquidez e, dado o papel dos depósitos bancários como forma de captação dos bancos, inibir as "corridas bancárias". Entre os instrumentos regulatórios destacavam-se limites de endividamento e alavancagem, índices de liquidez, limites à exposição de bancos a tomadores únicos e limites quanto à composição de ativos e à classe de atividades. ${ }^{8}$ No entanto, com o crescente distanciamento das questões que estimula-

\footnotetext{
8 Esses mecanismos limitavam o escopo da atuação das instituições e impunham controles quantitativos às operações autorizadas, entre os quais estavam índices de liquidez. Tal formato de regulação, marcado por controles diretos, caracterizaria o que Carvalho et al. (2015) compreendem como sendo o primeiro estágio da regulação financeira recente.
} 
ram a criação de tal conjunto de regras, este passou a ser questionado. Na década de 1970, ganhou corpo a ideia de que seguros de depósito, parte fundamental de tal instrumental, geravam risco moral, uma vez que os bancos acabavam por buscar posições mais arriscadas e não o contrário - ao assumir que iriam contar com a complacência do público, que não mais sofreria perdas em função da existência de seguro (CARVALHO, 2015). Nesse movimento, e em meio a um amplo e intenso processo de inovações financeiras, regras de restrição e controle tornaram-se inoperantes. $\mathrm{O}$ desenvolvimento da administração de ativos e passivos pelos bancos, ao lado do crescimento de mercados interbancários, ampliou o acesso à liquidez, gerando a crença de que problemas dessa ordem não mais ocorreriam. Observou-se, dessa forma, o desmantelamento da estrutura regulatória vigente até então, resultado da combinação de inovações financeiras e desregulamentação (MENDONÇA, 2012).

Nesse contexto, não sem responder a claros interesses, outro formato de regulamentação, então presente em maior ou menor grau em diferentes países, passou a ser mais amplamente discutido. Amparados na ideia da centralidade do risco das posições ativas dos bancos e calcados na exigência de relação mínima entre o capital próprio e os ativos em carteira, requerimentos mínimos de capital passaram a ocupar papel relevante nas discussões acerca da regulação. Isso, de alguma forma, significou mudança na lógica central da regulação: da preocupação com a liquidez, que aos olhos dos reguladores e mercados parecia não ser mais uma questão central, passou-se à preocupação com a solvência das instituições. Nas palavras de Carvalho et al. (2015),

[...] o que ameaçaria as instituições e, deste modo, o sistema de pagamentos que se quer defender, seria o risco excessivo assumido nas aplicações dos bancos. O objeto da regulação prudencial, assim, deveria ser a estratégia ativa dos bancos, mais do que o perfil de seus passivos, como no método anterior. (p. 448)

A justificativa para tal instrumental apresentava-se em dois níveis: (i) ao colocarem em risco seu próprio capital, os bancos seriam mais cuidadosos ao decidirem a composição de suas carteiras de ativos; e (ii) em situações adversas, teriam maior capacidade de resposta. Essa foi a lógica desenvolvida no âmbito do Comitê de Basileia que deu origem ao Acordo de 1988, doravante, Basileia I (ou BI).

\subsection{BASILEIA I}

Basileia I, que tinha como alvo os bancos internacionalmente ativos dos países do Grupo dos 10 (G10), anunciava dois objetivos: reforçar a solidez e a estabilidade do sistema bancário internacional e colocar uma estrutura de regras mais justa e consis- 
tente, que minimizasse as desigualdades competitivas entre os bancos internacionais (MENDONÇA, 2002, 2012). Naquele momento havia, de fato, uma grande diferença entre os requerimentos de capital exigidos pelos reguladores de diferentes países do G10, o que significava disparidades concorrenciais. A ideia então colocada era que os custos regulatórios deveriam ser os mesmos para as instituições atuantes no mercado internacional, de modo que a competição entre os bancos fosse pautada pela eficiência individual e não por vantagens regulatórias. ${ }^{9}$

Carvalho $(2005,2015)$ defende que BI tratava muito mais de custos de cumprimento da regulação do que de riscos e estabilidade, elencando diferentes argumentos para apoiar tal diagnóstico. De forma mais geral, seriam elementos explicativos o escopo de incidência do acordo - bancos internacionalmente ativos do G10 -, as referências à estabilidade internacional e a ausência de referências à estabilidade doméstica. O formato do acordo, marcado por largas faixas de categorias de ativos, pouco alinhadas aos riscos assumidos pelos bancos, mas amplamente representativas dos segmentos em que a concorrência entre os bancos se dá, também indicaria que sua preocupação maior seria nivelar a concorrência. De forma mais profunda, Cardim de Carvalho aponta a relação entre uma regulação marcada por requerimentos de capital associados aos riscos dos ativos e a tentativa de equalizar os custos da regulação em âmbito internacional. Uma explicação simples e direta para a escolha dos reguladores recair sobre capital e riscos, em sintonia com o objetivo de estabilidade, seria que a competição entre as instituições poderia desestabilizar o mercado bancário internacional, e lidar com as exposições de risco por eles em geral assumidas seria uma boa estratégia. ${ }^{10}$ Entretanto, o autor propõe uma leitura alternativa para a escolha dos requerimentos de capital a partir dos riscos. Partindo da premissa de que a assunção de mais riscos, pelos bancos, tende a elevar a rentabilidade, mas também a possibilidade de perdas, a pergunta era como a regulação prudencial poderia enfrentar tal situação. Seriam duas as respostas: (i) a exigência de requerimentos de capital em função dos riscos das posições assumidas imporia maiores custos para posições mais arriscadas, diminuindo sua rentabilidade; (ii) em países com redes de segurança e proteção mais robustas, a rentabilidade do sistema tenderia a ser relativamente maior, pois os bancos

9 Kregel (2006) apresenta uma linha de argumentação muito próxima à de Carvalho acerca do que seria a grande motivação de BI. E nos aponta as razões - relacionadas mais à política monetária do que à regulação prudencial - para serem mais elevadas as exigibilidades de capital impostas pelos reguladores dos EUA a seus bancos.

${ }^{10}$ Um indício dessa percepção seria a escolha das faixas de ativos com suas ponderações de risco, que representariam os segmentos nos quais os bancos internacionalmente ativos mais atuavam e, dessa forma, mais se expunham. 
com estratégias bem sucedidas poderiam usufruir de lucros mais altos, e aqueles com estratégias mal sucedidas teriam suas perdas bancadas pela sociedade. Como afirma Cardim de Carvalho:

If what is wanted is just to equalize regulatory costs, making them proportional to the relevant risks could be an efficient way of promoting more equitable competitive conditions while contributing to keep some modicum of financial stability. (2005, p. 5)

Destarte, na leitura do autor, explicita-se a percepção de que as insatisfações com o aparato da regulação prudencial não foram a principal motivação de BI, mas sim a questão concorrencial: a necessidade de nivelar o campo de jogo. Isso se colocava mesmo diante do quadro claro de dissolução de parcela importante da regulação até então vigente, causado pelo intenso e longo processo de inovações financeiras e pelos movimentos de desregulamentação.

A adesão a Basileia I, de fato, tomou proporções muito mais amplas do que as esperadas no que concerne ao número de países que o adotaram - mais de 120 -, bem como ao escopo, pois, na grande maioria dos países, o acordo foi implementado nos sistemas bancários como um todo, e não só nos bancos internacionalmente ativos. Dessa forma, acabou por ocupar um papel diverso e mais importante do que o inicialmente previsto e gerou uma harmonização dos arcabouços regulatórios vigentes em grande parte dos sistemas bancários mundiais.

Muitas críticas foram dirigidas à padronização de regras trazida por Basileia I, ou seja, ao formato estrito das categorias de ativos e de riscos estabelecidas, que estimulariam operações de arbitragem, as quais refletiriam, em especial, o descolamento entre o capital requerido pela regulação e o então chamado capital econômico, resultado do desenvolvimento de modelos internos de riscos. ${ }^{11} \mathrm{Ou}$ seja, a divergência entre capital regulatório e capital econômico, que levava à arbitragem, seria fruto do distanciamento entre as regras e as práticas do mercado, isto é, entre regulação e comportamento das instituições. Dessa forma, pressões se acumularam no sentido de flexibilizara padronização de Basileia I e atender às chamadas práticas de mercado, incorporando o desenvolvimento na mensuração e administração dos riscos. ${ }^{12}$ Tam-

11 Provocando piora na qualidade das carteiras dos bancos, com a diminuição da participação de tomadores mais seguros e o encurtamento dos prazos.

12 Nesse sentido, a emenda de 1996 foi criada para incorporar o risco de mercado por meio do uso de modelos internos. 
bém precisa ser observado que Basileia I não incorporava de forma adequada o risco advindo de ativos que passaram a ocupar papel relevante nos balanços dos bancos: instrumentos securitizados e derivativos.

Em sua análise das virtudes e limites de Basileia I, Carvalho (2005) aponta qual seria sua principal fraqueza. Para o autor, BI partia de um modelo de banco comercial tradicional, nos moldes de um sistema segmentado - que, nos Estados Unidos, naquele momento, já não mais existia - e ignorava o modelo de banco universal, o mais comum em outras nações. Isso teria fragilizado seus resultados, favorecendo bancos que já operavam em mercados de títulos, como os europeus, estimulando operações securitizadas. Nas palavras do autor, Basileia I "stimulated banks to shift their activities towards securities markets to reduce the burden of compliance with regulation" (CARVALHO, 2005, p. 7).

A ampla adesão a Basileia I - que se tornou peça central da regulação prudencial de muitos países -, o tratamento limitado dos riscos e as pressões que se acumulavam levaram a dois movimentos: à emenda de 1996, com a incorporação dos riscos de mercado e dos modelos internos dos bancos, e a um processo de revisão do Acordo de 1988. Carvalho (2005) destaca que o papel assumido por Basileia I na regulação prudencial de vários países, se não era objetivo central do Comitê, foi por esse amplamente acolhido, o que também evidenciou suas limitações e levou a uma revisão:

As most of the world embraced Basel I as the basis of the new thinking in prudential regulation, its shortcomings became more and more visible forcing the Committee to proceed to a deep revision of the original work. (CARVALHO, 2005, p. 9)

\subsection{BASILEIA II}

Como resultado desse processo, e como parte de movimentos mais amplos de transformação de arcabouços regulatórios, Basileia II foi publicado em 2004. Manteve como instrumento central os requerimentos mínimos de capital, ponderados pelo risco dos ativos. Contudo, sua maior complexidade, em claro contraste com a simplicidade de Basileia I, refletia importantes mudanças. Como premissa central, apesar de poucas alterações no que concerne aos objetivos anunciados, Basileia II explicitou a busca por solidez e resiliência dos sistemas bancários, cerne da regulação prudencial. Para enfrentar o amplo escopo abrangido, isto é, sistemas bancários como um todo, e respondendo a muitas pressões, em especial as advindas das próprias instituições financeiras, abandonou a padronização característica de Basileia I, em um explícito movimento de flexibilização. Essa resultou, efetivamente, não só das diferentes possibili- 
dades de enquadramento dos ativos, mas também, e especialmente, da incorporação de métodos de mensuração e administração de riscos desenvolvidos por instituições privadas. E passou a tratar, além dos riscos de crédito e de mercado, do risco operacional. O resultado gerado, tendo como referência Basileia I, foi uma estrutura mais sensível ao risco - na verdade, à leitura privada dos riscos -, uma vez que trouxe para o âmago da regulamentação as práticas de mercado, seja por meio dos modelos internos de avaliação de riscos, seja por meio de avaliações das agências de rating. Outro elemento fundamental de Basileia II é que, apesar de exigir capital de instrumentos securitizados e derivativos, em operações no balanço e fora deste, e de ser aplicado de forma consolidada, continuou centrada nos bancos, individualmente. Dessa forma, a regulamentação ignorou a interpenetração das funções de bancos e não bancos, assim como seus efeitos sobre o sistema (MENDONÇA, 2012). Seu foco continuou a ser microeconômico - isto é, as exigências impostas aos bancos, individualmente - e não macroeconômico (DEOS, 2012).

Carvalho $(2005,2015)$ discorda frontalmente da ideia de que exista uma continuidade entre BI e BII e de que este último teria sido uma evolução do primeiro, com a incorporação de algumas mudanças e aperfeiçoamentos de natureza técnica. ${ }^{13}$ Para o autor, Basileia II trouxe mudanças claras com relação ao escopo e à própria natureza do arcabouço de regras. Quanto ao escopo, se BI tratava muito mais de garantir o nivelamento das condições de concorrência entre bancos internacionais do que de garantir a estabilidade sistêmica, sobretudo doméstica, Basileia II tinha no centro a questão da estabilidade, um desafio muito mais complexo e que impunha mudanças importantes ao conjunto de regras.

(...) in contrast to Basel I, Basel II does not reach for what is common in banks but for what is specific to each institution. Each bank, and in particular the complex universal banks we find everywhere in the 2000s, is a particular combination of investment opportunities and risks. Basel II aims at defining instruments to deal with this diversity and idiosyncrasy. (CARVALHO, 2015, 49)

Para enfrentar tal desafio, optou-se por uma clara mudança de rota. Basileia II estimulou bancos a mensurar e administrar seus riscos, a partir do pressuposto de que métodos mais alinhados com as práticas do mercado seriam mais eficientes do que uma regulação restritiva. Caberia aos reguladores a indução do comportamento espe-

${ }^{13}$ O próprio tamanho dos documentos seria indicativo: se BI, com seus anexos, foi apresentado em 28 páginas, a versão “revisada” configurou-se em 239 páginas (CARVALHO, 2005). 
rado, e não a imposição de regras estritas (CARVALHO, 2005, 2015). Em assim sendo, no movimento de Basileia I para II, a preocupação central passou a ser a regulação prudencial com um conjunto de regras ao mesmo tempo mais complexo e menos prescritivo, mais próximo às práticas de mercado.

As críticas mais recorrentes à Basileia II referiam-se a sua elevada complexidade que, entre outros limites, impunha dificuldades importantes de implementação, inclusive por atribuir muitas funções aos supervisores, nem sempre aptos a desempenhá-las. Adicionalmente, e a despeito da inclusão da disciplina de mercado em sua estrutura, como terceiro pilar, sugeriam que o papel por essa ocupado em Basileia II seria pouco relevante. As críticas também apontavam que Basileia II estimularia o caráter pró-cíclico do mercado, ao se amparar na leitura de risco dos agentes; que induziria a uma retirada de posições dos balanços dos bancos; e, ainda, que abriria mais espaços para fraudes, pois a redução de requerimentos de capital eleva os ganhos potenciais dos bancos.

No entanto, Carvalho (2014) destaca que poucos críticos foram ao ponto de maior fragilidade de Basileia II, que seria seu foco microeconômico, isto é, nas instituições bancárias individuais, a partir da premissa de que a segurança sistêmica resultaria da segurança individual dos bancos, obtida pela indução a uma melhor administração de riscos. Para o autor, a CGF explicitou o equívoco dessa premissa, pois efetivamente o risco sistêmico afeta os riscos individuais. Muitos dos parâmetros que norteiam os modelos de risco e, assim, amparam as decisões dos bancos, são endógenos ao funcionamento do sistema bancário como um todo, ou seja, refletem o ambiente econômico e financeiro. Ademais, cálculos de risco assumem que o passado se repetirá no futuro, o que, sob incerteza fundamental Keynesiana, não ocorre. Diante do risco sistêmico, a utilidade dos modelos de administração de risco desaparece: "[b]oth, financial institutions and regulators were reminded of this basic truth yet again when all risk calculations prescribed by BII turned out to be wrong" (CARVALHO, 2015, p. 49).

Uma parcela expressiva dos problemas e limitações de Basileia II foi exposta, com muita força, com a eclosão da GCF, que "atropelou” seu processo de implementação. A crise mostrou como Basileia II agravava o caráter pró-cíclico do comportamento dos bancos. E, mais importante, explicitou que a regulação amparada em requerimentos de capital ponderados pelo risco dos ativos havia estimulado os bancos a removerem exposições de seus balanços, o que era possibilitado pela securitização. E isso dificultava a percepção de reguladores, investidores e parceiros de negócios acerca dos ris$\cos .{ }^{14}$ Os bancos, transformadores de prazos, se amparam em funding de curto prazo

\footnotetext{
14 "Após a crise, políticos e supervisores frequentemente enfrentaram as críticas afirmando que possivelmente não teriam como saber o que os bancos estavam fazendo porque estes utilizavam uma complexa rede de veículos off-shore e fora do balanço na condução dos seus negócios" (PERSAUD, 2012, p. 294).
} 
- e, naquele momento o faziam intensamente, em especial nos chamados mercados de recompra, ou repo - que desaparecem quando há perda de confiança (STIEFMUELLER, 2018). Com isso, passaram a enfrentar problemas de iliquidez, que, em muitos casos, se transformaram em problemas de insolvência. ${ }^{15}$ E não havia, no aparato tanto de Basileia I, quanto no de Basileia II, qualquer tratamento do risco de iliquidez. Por fim, como colocado por Carvalho (2015), diante de uma crise sistêmica, ficaram claros os limites da regulação centrada no risco individual dos bancos. Efetivamente, o ambiente no qual se deu a gestação da crise, com as proporções e intensidade observadas, era marcado por uma estrutura regulatória que pouco restringia as operações dos agentes e também pouco lhes impunha.

\subsection{BASILEIA III}

Imediatamente após a falência do banco de investimentos Lehman Brothers, em clima de muita tensão em âmbito mundial, houve intensa pressão política para ampliar e reforçar o sistema de coordenação internacional, dada a necessidade de enfrentar a situação com ações articuladas, bem como de evitar novas crises. Isso implicava, segundo a percepção então dominante, introduzir reformas relevantes na arquitetura, na regulamentacão e na supervisão do sistema. Foi nesta conjuntura, isto é, quando a CFG estava ainda latente na memória e muitos países enfrentavam retração severa no nível de produto que se deu a criação do Financial Stability Board (FSB), na segunda cúpula de líderes do Grupo dos 20 (G20), realizada no primeiro semestre de 2009. O objetivo do FSB era coordenar, em nível internacional, o trabalho das autoridades regulatórias nacionais, bem como dos organismos multilaterais (DEOS, 2012).

Uma nova proposta para o sistema bancário - Basileia III - foi apresentada na cúpula do G20 em Seul, em novembro de 2010. Seu objetivo seria reforçar a regulação individual (sobre os bancos), com vistas à maior capacidade de resistência a crises. Também teve como objetivo incorporar uma dimensão macroprudencial para lidar com o caráter pró-cíclico e com o risco sistêmico. Para dar conta dessas tarefas, Basileia III buscou elevar o volume de capital retido pelos bancos, assim como a qualidade do capital - movimento consagrado na expressão mais e melhor capital. Adicionalmente, passou a exigir dos bancos a manutenção de um volume adicional de capital, para funcionar como um amortecedor anticíclico. Outra modificação importante, relativamente aos acordos anteriores, foi a introdução de um índice de alavancagem

\footnotetext{
15 Vale lembrar que quando da crise, muitos dos bancos que faliram e/ou sofreram intervenção apresentavam índices de capital compatíveis com as exigências regulatórias.
} 
sharp de capital, relativamente ao total da exposição, isto é, um montante de capital que não fica sujeito à avaliação de risco. Basileia III introduziu, ainda, requerimentos de liquidez, inexistentes no acordo anterior (DEOS, 2012).

Basileia III teve como ponto de partida Basileia II, mas exigiu mais e melhor capital para fazer frente aos ativos ponderados pelos riscos. Paralelamente, como apontado, introduziu novas exigências de capital. Assim, se a lógica da nova regulação bancária manteve o pressuposto de que cabe ao mercado, em boa medida, a tarefa de avaliar seus próprios riscos, tornou relativamente mais caro, em termos de capital exigido, qualquer ativo mantido no portfólio das instituições. Por fim, uma diferença importante foi o reconhecimento, por parte dos reguladores, da impossibilidade de ancorar a segurança do sistema apenas nas avaliações feitas pelo mercado e na dimensão micro, reconhecendo o comportamento pró-cíclico do sistema, bem como as limitações do modelo de autoavaliação de riscos. Por isso foram feitas exigências de capital contra-cíclico e de capital puro.

As exigências de capital contra-cíclico foram incorporados a Basileia III a partir do diagnóstico de que o comportamento pró-cíclico dos agentes de mercado foi desestabilizador quando da crise. ${ }^{16}$ Autoridades reguladoras podem ativar requerimentos de capital adicionais - entre $0 \%$ e $2,5 \%$ - a partir da percepção de crescimento inadequado do crédito, com o propósito de “(...) atingir o objetivo mais amplo de proteger o setor bancário em períodos de crescimento excessivo do crédito agregado" (BCBS, 2010, p. 7). E podem desativá-los, em situações de desaceleração, estresse e fragilidade. Em outras palavras, esses requerimentos extras têm como intuito diminuir a amplitude do ciclo de crédito. Vale notar que, segundo o BCBS (2010), a preocupação com o caráter pró-cíclico do comportamento dos agentes já estava presente em Basileia II, o que teria se explicitado na construção de salvaguardas. No entanto, Basileia II, ao incorporar ao arcabouço regulatório a leitura e a avaliação de riscos feita pelos agentes de mercado, amplifica o comportamento pró-cíclico do sistema. Nesse sentido, Cardim de Carvalho destaca que as exigências de capital em discussão, introduzidas em Basileia III, vieram a responder à percepção da natureza pró-cíclica de Basileia II, pois trata “ [...] de compensar a tendência do Basileia II de acentuar flutuações cíclicas da economia, como inevitavelmente ocorre com qualquer método de regulação prudencial sensível a riscos" (ANBIMA, 2010, p. 32).

\footnotetext{
${ }^{16}$ Segundo o Comitê de Basileia (BCBS, 2010) isto passou a ser feito de duas formas, por meio do capital regulamentar - para se evitar que o mínimo de capital seja atingido - e por meio da introdução de novos requerimentos.
} 
Uma questão que estão se coloca refere-se aos possíveis efeitos destes novos requerimentos. A introdução de novos requerimentos de capital impõe maiores custos aos bancos, o que, em princípio e em algum grau, pode afetar seu comportamento: mais afeitos à aceitação de maiores riscos no desenrolar da fase ascendente e menos afeitos, na fase descendente, como apontado por Minsky. No entanto, dado que tais comportamentos são inerentes às instituições bancárias, não seria possível erradicá-los, sob o risco de inviabilizar o sistema. Ademais, podem se colocar limites às decisões de imposição de requerimentos de capital adicional, bem como a seus efeitos sobre o crédito. Em determinadas situações, autoridades reguladoras podem se mostrar pouco propensas a ativar o aumento do capital com o intuito de frear um ciclo de crescimento do crédito. ${ }^{17} \mathrm{E}$, se ativadas as novas exigências, resta pensar sobre seus efeitos. Diferentes estudos empíricos apontam a baixa sensibilidade do crédito a alterações nos requerimentos de capital, como pode ser depreendido de Mendonça et al. (2017).

Também foi reconhecido pelos policy makers que a liquidez desaparece nas crises e que os bancos precisam manter um nível mínimo de ativos líquidos para enfrentar situações de stress nas quais o mercado tende a travar (DEOS, 2012).

A introdução de índices de alavancagem puro e de liquidez vai ao encontro do entendimento existente na tradição de Minsky-Kregel acerca do que confere robustez aos sistemas bancários. Isso porque, da atuação dos bancos, marcada por elevado nível de alavancagem e descasamento de prazos entre ativos e passivos, emergem problemas de liquidez e insolvência. Nesse sentido, algum nível de controle da alavancagem, sem a mediação dos riscos embutida nos índices de capital, bem como a imposição de índices de liquidez pode colaborar para uma maior robustez das posições dos bancos.

Carvalho (2014) entende ser BIII uma proposta de regulação híbrida, quase uma combinação de emendas ao acordo anterior, construída a partir de dois diferentes diagnósticos. Primeiramente, há o diagnóstico de que BII estava conceitualmente correta, mas pouco calibrada. Seu conceito de capital seria muito amplo e incluiria instrumentos que acabavam por contaminá-lo. A solução encontrada foi introduzir em Basileia III, como já apontado, mais e melhor capital.

Um segundo diagnóstico, uma inovação na trajetória dos Acordos de Basileia, vai ao encontro da leitura na tradição Minsky-Kregel, incorporada por Cardim de Carva-

17 Em março de 2019, o Federal Reserve decidiu por não elevar o colchão de capital contra-cíclico, mantendo-o em $0 \%$. Isto seria parte de um posicionamento mais amplo da gestão Trump, que defende que “(...) deregulation will spur economic growth by freeing banks to make more loans" (NYT, 2019). 
lho e utilizada neste trabalho: a percepção de que, em algum grau, a fragilidade do sistema financeiro resulta da combinação de alta alavancagem e desencontro de prazos. Seriam três os indícios de que o Acordo incorporou esse segundo diagnóstico. Primeiro, a conclusão de que o risco sistêmico resulta de interconexões, o que de alguma forma problematiza a concepção de regulação micro, focada na instituição. ${ }^{18}$ Um segundo indício seria a introdução de um índice de alavancagem puro, que acaba manifestando uma ambiguidade de Basileia III: a coexistência de dois tipos de instrumentos para o tratamento da alavancagem, que partem de concepções muito distintas (CARVALHO, 2014, 2015). ${ }^{19}$ Por fim, a terceira evidência seria a introdução de índices de liquidez, mesmo que ainda de forma tímida. No entanto, e a despeito dessa medida, o arcabouço regulatório ainda pecaria por menosprezar a centralidade da liquidez gerada pelo sistema bancário para o adequado funcionamento da economia, o que está para além da própria questão da robustez desse sistema. Carvalho (2014) aponta que seria necessário, assim:

[...] a better treatment of the need to guarantee the system's liquidity: to make banks rebuild their basic function of acceptance, that is, the creation of liquidity against the purchase of illiquid liabilities issued by income creators. (CARVALHO, 2014, p. 361-362)

\section{CONSIDERAÇÕES FINAIS}

O presente trabalho teve como objetivo discutir a regulação bancária, em especial em seu formato recente, amplamente adotado por um grande número de países - os Acordos de Basileia I, II e III. Procurou-se, à luz de autores centrais, investigar os movimentos entre esses, buscando compreender a que interesses e/ou motivações respondiam, bem como o significado dos ajustes e/ou redefinições que ocorreram. Para tal, partiu-se de um instrumental conceitual na tradição de Keynes-Minsky, tendo se apoiado de forma mais específica nas contribuições de Jan Kregel e, em especial, de Fernando Cardim de Carvalho.

A partir da discussão conceitual e dadas as peculiaridades, a importância sistêmica e o comportamento das instituições bancárias, fica clara a ideia de que essas têm que

18 Carvalho entende serem evidentes as dúvidas do Comitê sobre como enfrentar tal questão.

19 São eles os índices de capital, construídos dentro da lógica de melhorias das técnicas de administração de riscos, e os índices de alavancagem, elaborados por meio do cálculo direto, sem ponderações de risco, que implica uma volta a um estilo de regulação mais prescritiva sobre o comportamento dos bancos. 
ser reguladas. A questão que se coloca é a de como fazê-lo, isto é, qual o formato que a regulação deve assumir. Os acordos de Basileia apoiam-se nos requerimentos de capital, sendo que somente em Basileia III, após a CFG, agregaram-se exigências quanto à liquidez, ainda que essas não ocupem papel central no arcabouço. A ideia que estaria por trás da adoção de requerimentos de capital apresentava-se em dois níveis: os bancos seriam mais cuidadosos ao decidirem a composição de suas carteiras de ativos, uma vez que colocariam em risco seu próprio capital, e teriam maior capacidade de resposta em situações adversas. Kregel e Cardim de Carvalho apontam limites importantes à regulação de capital ao indagarem se esta contribui para atenuar o comportamento das instituições financeiras, que tendem a assumir posições de maior fragilidade na fase ascendente do ciclo econômico. O que se pode afirmar é que a CFG foi gestada e se explicitou em um ambiente regulatório do "tipo" Basileia, que não foi capaz de impedi-la. Ao contrário, alguns autores apontam que pode ter contribuído para sua formação ou mesmo limitado as condições para seu enfrentamento. Ademais, Basileia I e II não se ocuparam de uma variável que é, efetivamente, central para a determinação da segurança das atividades dos bancos, vale dizer, a liquidez e os riscos a ela associados. Após a CGF, não foi mais possível ignorar a questão da liquidez, inserida em Basileia III, mesmo que timidamente, pois foi mantido seu eixo central, o das exigências de capital ponderadas pelo risco.

Cardim de Carvalho, de forma específica, é bastante crítico com relação à importância conceitual do capital bancário e, dessa forma, ao arcabouço regulatório construído a partir da imposição de requerimentos de capital. Esses seriam pouco efetivos para limitar a tendência a comportamentos especulativos que são inerentes aos bancos e geradores de fragilidade financeira sistêmica. E também seriam pouco capazes de lidar com o risco de iliquidez inerente às operações bancárias, que são alavancadas e têm descasamentos de prazos. Na verdade, o capital bancário seria teórica e historicamente irrelevante, sendo a liquidez a variável central para a segurança das atividades dos bancos. Para Cardim de Carvalho, a liquidez deveria estar no centro do arcabouço regulatório.

Em resposta à grande crise dos anos 1930, um importante e longevo aparato regulatório foi montado, dentro de uma lógica restritiva/prescritiva, marcando a estrutura e afetando a dinâmica financeira. Tal aparato passou a ser corroído por inovações financeiras e foi desmantelado em um importante processo de desregulamentação ocorrido nas décadas de 1980 e 1990. Alguns poderiam afirmar que Basileia I significou um movimento de re-regulamentação a partir de uma nova lógica, movimento que foi aprofundado em Basileia II e, com algumas diferenças, em Basileia III. Contudo, o que houve foi um processo de acomodação e de aceitação das inovações por parte das autoridades regulatórias, que não impuseram limites ou restrições à dinâmica do 
mercado. ${ }^{20}$ A Basileia I, mais padronizado e, em algum grau, mais impositivo, seguiu-se Basileia II, mais flexível e menos restritivo. Quando se toma como ponto de partida para a análise da regulação a grande crise da década de 1930, o movimento do pêndulo, de Basileia I para Basileia II, é muito claro: de uma regulação mais restritiva para uma que limita menos. De fato, as mudanças entre BI e BII não se deram como reação a uma crise de grande envergadura, mas como adequação, quase que "natural", aos movimentos do mercado. E nem mesmo, o que é mais enigmático, a eclosão da maior crise financeira internacional desde os anos 1930 alterou essa trajetória. A resposta regulatória à $\mathrm{CFG}$, Basileia III, ainda que tenha trazido regras mais restritivas no que concerne à liquidez e alavancagem, não promoveu mudanças profundas: a regulação se adequou à dinâmica presente, ao invés de tentar forjar uma nova.

Adotou-se no presente trabalho a hipótese de Minsky (1994), também presente em Carvalho (2014), de que o movimento da regulação é cíclico, ou pendular. Em situações de crise, quando a estabilidade do sistema é posta em xeque, há uma intensificação da regulação, como ocorreu nos anos 1930 e, em algum grau, após a CFG. À medida que a crise vai se tornando parte do passado, o arcabouço regulatório, com custos altos e muitas interdições, passa a ser questionado. Nesse movimento, os agentes financeiros - bancos entre eles -, imersos na dinâmica da concorrência intercapitalista, inovam e pressionam para que sejam atenuados os limites colocados pela regulação. Com isso, a regulação é crescentemente tensionada e transformada.

Contudo, é preciso também refletir sobre esses movimentos a partir de uma lente de alcance mais profundo, que capte as alterações não só nas estruturas financeiras, mas também nas estruturas capitalistas. A grande crise dos anos 1930 e as mudanças no aparato regulatório que a ela se seguiram impuseram uma estrutura financeira que implicou uma nova dinâmica capitalista, inaugurando o que Minsky chamou de managerial capitalism. Naquele aparato havia um claro entrelaçamento entre regulação prudencial e estrutura financeira. Basileia I, por sua vez, mesmo se for entendido como instrumento de harmonização da concorrência entre bancos internacionais, foi instaurado no bojo do esgarçamento da estrutura e da dinâmica anteriores. E acoplou-se ao surgimento de uma nova dinâmica, que Minsky denominou como money manager capitalism. Implicou, no sentido mais amplo aqui tratado, um maior distanciamento entre a regulação prudencial, menos restritiva e mais prescritiva, e a determinação da estrutura financeira, ou de

${ }^{20}$ Não ignorarmos, na verdade, de alguma forma, concordarmos, com a análise de Carvalho de que Basileia I não se tratava de regulação prudencial, mas sim de regulação para nivelar as condições de concorrência dos bancos internacionalmente ativos, leiam-se, norte-americanos e japoneses. Fazemos isso por acreditarmos que tal percepção não inviabiliza o argumento aqui desenvolvido de que Basileia I inauguraria uma nova lógica da regulação, que foi amplamente aprofundada com Basileia II: a acomodação à e não imposição de dinâmica financeira. 
um regime financeiro. Na verdade, Basileia I partiu da estrutura que foi talhada a partir de inovações financeiras, explicitando um longo e importante movimento do pêndulo. Nesse sentido, Basileia II avançou e inovou ao aproximar o esquema regulatório à dinâmica financeira então vigente, possibilitando e até contribuindo para seu aprofundamento. Assim, levou ao limite a lógica de que a regulação prudencial parte da estrutura e da dinâmica, ao invés de determiná-las. E foi nesse ambiente que a maior e mais profunda crise financeira desde aquela observada na década de 1930 foi forjada. Basileia III veio em resposta à CFG, inaugurando um esquema híbrido, marcado pela combinação entre a lógica regulatória prescritiva e algumas restrições. De qualquer modo, mesmo que mais restritiva, não impôs uma nova estrutura financeira, adaptando-se à então observada. Houve um movimento do pêndulo, mas não uma mudança na estrutura, o que talvez explique a rapidez com que vem sendo questionada.

Isso posto, e a despeito de sua potência e da extensão de seus efeitos, a reação regulatória que se deu após a CFG não transformou o sistema financeiro. Stiefmueller (2018) aponta alguns indicadores nesse sentido: uma década após a crise, o mercado de derivativos não foi substantivamente reduzido, sendo em 2017 apenas $8 \%$ inferior a 2007. A simbiose entre bancos de investimento e bancos comerciais prosseguiu, e tampouco foram desarticulados os bancos gigantes, complexos e opacos - as instituições conhecidas como grandes demais para falir. Nesse contexto,

It is fair to say that Basel III has not conclusively solved these problems. It still relies on the same approach that doomed Basel II, i.e. risk models of stunning, and self-defeating, complexity in the hands of the very same banks that are meant to be regulated by them. For regulators, investors and the general public, these risk models still are, effectively, 'black boxes'. Consequently, it is illusory to expect investors to rein in wayward banks by exercising 'market discipline'. (STIEFMUELLER, 2018, p. 23)

Isso talvez explique porque, passados 10 anos da CFG, e sendo seus efeitos ainda sentidos em diferentes aspectos - econômicos, políticos, sociais e até mesmo culturais - já se observem pressões para que sejam atenuadas as mudanças regulatórias criadas em seu bojo. Nos últimos anos, observou-se uma tendência de suavizar a "re-regulação" tanto na Europa quanto nos Estados Unidos, onde o Congresso, em 2018, aprovou algumas medidas de "recuo" no arcabouço legal - o Dodd Frank Act. Milhares de bancos pequenos e médios foram, com isso, "liberados" de medidas de regulação e supervisão mais restritivas. Em maio de 2018, o Federal Reserve, banco central dos Estados Unidos, iniciou um movimento de "suavização" da Volcker Rule, dando maior liberdade para as operações de tesouraria proprietária. Enfim, onde estamos 10 anos após a crise? Poucos avanços e muitos recuos importantes. 


\section{REFERÊNCIAS}

ANBIMA - ASSOCIAÇÃO BRASILEIRA DAS ENTIDADES DOS MERCADOS FINANCEIRO E DE CAPITAIS. Basileia III: Novos desafios para a adequação da regulação bancária. Perspectivas Anbima, dez. 2010.

BCBS - BASLE COMMITTEE OF BANKING SUPERVISION. Basel III: A global regulatory framework for more resilient banks and banking systems. Basel: Bank of International Settlements, Dec. 2010.

CARVALHO, F. J. C. Basel II: a critical assessment. Texto para Discussão do IE-UFRJ, n. 3, mar. 2005.

CARVALHO, F. J. C. Regulação prudencial na encruzilhada: depois de Basiléia II, o dilúvio? In: PAULA, L. F. de; OREIRO, J. L. (Orgs.). Sistema Financeiro: uma análise do setor bancário brasileiro. 1ed.Rio de Janeiro Campus/Elsevier, 2007.

CARVALHO, F. J. C. Can Basel III work when Basel II didn't? In: PAPADIMITRIOU, D. (Org.). Contributions to economic theory, policy, development and finance: essays in honor of Jan A. Kregel. 1. ed. Londres: Palgrave MacMillan, 2014, v. 1.

CARVALHO, F. J. C. Basel Agreements. In: ROCHON L.P.; ROSSI, S. (Org.). The encyclopedia of central banking. 1 ed. Cheltenham: Edward Elgar, 2015.

CARVALHO, F. J. C. et al. Economia Monetária e financeira: teoria e prática. Rio de Janeiro: Editora Campus, 2015.

DEOS, S. A regulação do sistema financeiro após a crise. In: CINTRA, M. A.; GOMES, K. (Orgs.). As transformações no sistema financeiro internacional. 1. ed. Brasilia: IPEA, 2012, v. 1.

IMF - INTERNATIONAL MONETARY FUND. World Economic Outlook: challenges to steady growth. Washington, DC: IMF, Oct. 2018a.

IMF - INTERNATIONAL MONETARY FUND. Global financial stability report - a decade after the global financial crisis: are we safer? Washington, DC: IMF, Oct. $2018 \mathrm{~b}$.

KREGEL, J. Margins of safety and weight of the argument in generating financial fragility. Journal of Economic Issues, v. 31, n. 2, 1997.

KREGEL, J. The past and future of banks. Quaderni di Ricerche, Rome, Ente Luigi Einaudi, n. 21, 1998.

KREGEL, J. O novo Acordo de Basiléia pode ser bem sucedido naquilo em que o acordo original fracassou? In: MENDONÇA, A. R. R.; ANDRADE, R. (Orgs.). Regulação bancária e dinâmica financeira: evolução e perspectivas a partir dos acordos de Basileia. Campinas: UNICAMP, 2006.

MENDONÇA, A. R. R. de. Os Acordos de Basileia: uma avaliação do novo formato da regulação bancária. Tese (Doutorado em Economia) - Instituto de Economia, Universidade Estadual de Campinas, Campinas, São Paulo, 2002.

MENDONÇA, A. R. R. Regulação bancária e arranjo institucional pós-crise: atuação do Conselho de Estabilidade Financeira e Basileia III. In: CINTRA, M.; GOMES, K. G. (Orgs.). As transformações no sistema financeiro internacional. 1. ed. Brasília: IPEA, 2012, v. 2. 
MENDONÇA, A. R. R.; DEOS, S.; BULLIO, O., ULTREMARE, F. Basileia III no Brasil: institucionalidade e efeitos sobre o crédito. In: ENCONTRO NACIONAL DE ECONOMIA POLÍTICA, Sociedade de Economia Política, 12, Campinas, SP, 2017.

MINSKY, H. John Maynard Keynes. New York, Columbia University Press, 1975.

MINSKY, H. Stabilizing an unstable economy. 1. ed. New Haven, Yale University Press, 1986.

MINSKY, H. Schumpeter: finance and evolution. In: HEERTJE, A.; PERLMAN, M. (Eds.). Evolving technology and market structure. Ann Arbor, MI: University of Michigan Press, 1990.

MINSKY, H. Schumpeter and finance. In: BIASCO, S.; RONCAGLIA, A.; SALVATI, M. (Eds.). Market and institutions in economic development. New York: St. Martin Press, 1993.

MINSKY, H. Regulation and Supervision. Levy Economics Institute Paper, Annandale-on-Hudson, n. 443, 1994.

NYT - NEW YORK TIMES. Condemned to repeat the history of bank failures? The NYT Editorial Board, March 20, 2019.

STIEFMUELLER, C. Ten years after: back to business as usual. the pit and the pendulum - postcrisis financial regulation in Europe. Brussels: Finance Watch, 2018.

TYMOIGNE, E.; WRAY, L. R. The rise and fall of money manager capitalism: Minsky's half century from World War Two to the Great Recession. London and New York: Routledge, 2014.

WRAY, L. R. The rise and fall of money manager capitalism: a Minskian approach. Cambridge Journal of Economics, v. 33, n. 4, p. 807-828, 2009. 